\title{
Incidence of cancer among Norwegian boiler welders
}

Tor Erik Danielsen, Sverre Langård, Aage Andersen

\begin{abstract}
Objectives-The cancer incidence among 2957 boiler welders was investigated. The subjects were registered electrical welders from 1942 to 1981. A subcohort of 606 stainless steel welders was studied separately.

Methods-The investigation was a historical prospective cohort study based on a national registry. The loss of follow up was $4 \cdot 9 \%$.

Results-There were 625 deaths (659 expected). There were 269 cancer cases (264 expected). An excess of lung cancer was found; 50 cases $v 37 \cdot 5$ expected. There were three cases of pleural mesotheliomas $v 1 \cdot 1$ expected. The subcohort of stainless steel welders had six cases of lung cancer $v$ $5 \cdot 8$ expected, and one case of pleural mesothelioma $v 0.2$ expected.

Conclusions-The welders in the study were assumed to represent a qualified work force. These welders had a small excess risk of lung cancer. The excess risk did not seem to be associated with stainless steel welding. Smoking and asbestos exposure were potential confounders.
\end{abstract}

(Occup Environ Med 1996;53:231-234)

Keywords: leukaemia; lung cancer; welding

Welders are involved in a variety of processes resulting in different work related exposures. The specific exposure from welding fumes depends on the composition of the base material and on the applied welding processes. Several studies have been conducted to assess the possible relations between exposure to welding fumes and the development of lung cancer. ${ }^{1-11}$ These have indicated that the risk of lung cancer among welders, possibly related to their exposures during welding, is increased by $30-40 \% .{ }^{12}$ Tobacco smoking, asbestos, and other work related exposures have been regarded as potential confounders in studies among welders. ${ }^{13}$

Fumes from stainless steel welding contain compounds of nickel and chromium, which have been shown to be carcinogenic to humans. ${ }^{14}$ The excess risk of cancer among welders has been tentatively attributed to subgroups of welders welding mainly stainless steel and their exposure to hexavalent chromium. ${ }^{4}$

The present study comprises a cohort of registered Norwegian boiler welders. The aim was to investige the incidence of lung cancer in a large group of welders including stainless steel welders, and is a part of a project on health hazards of welding. ${ }^{23}$

\section{Material and methods}

SOURCES

The National Registry of Boiler Welders was established in 1942. The registry was established to ensure that boiler welders had appropriate training and welding experience, and has been administered by a branch of the Labour Inspectorate of Norway until 1992.

The registry comprises three different types of records;

(a) information on each welder's registration, method of welding, and alloys that the certificate was valid for;

(b) records on businesses of interest including the names of the welders registered during employment; and

(c) correspondance files containing a formal application form for most welders with information on previous work experience and education.

The welders were all registered by name, date of birth, and the first and latest date of registration. There was no corresponding information on the end of welding activity. Registration for, or previous work as a stainless steel welder, was always recorded.

All businesses engaged in manufacturing and maintenance of pressure boilers used selected registered welders. The welders included in the present study are highly qualified welders, thus comprising a stable work force.

HISTORICAL ASSESSMENT OF EXPOSURE

The investigation was limited to welders registered in electric welding. Many of the welders registered for electric welding had experience of gas welding.

In the early years manual metal arc welding was the predominant method. In the 1970s the number of welders certified for gas shielded methods, including tungsten inert gas welding, increased gradually. The registry comprised welders from 385 different businesses located throughout the country. These had a variety of working conditions. Data on environmental monitoring were not available from any of the businesses covered by the registry. Information from other studies indicate that the working conditions gradually improved and that personal airway protection was widely available from the early 1970 s onwards. ${ }^{310}$ 
Table 1 Observed (O) and expected (E) cases of cancer at selected sites in 2957 boiler welders

\begin{tabular}{lrrr}
\hline Cancer site (ICD-7) & \multicolumn{1}{l}{$E$} & $S I R(95 \% \mathrm{CI})$ \\
\hline Oesophagus (150) & 2 & $3 \cdot 2$ & $63(6-225)$ \\
Stomach (151) & 17 & $19 \cdot 8$ & $86(50-137)$ \\
Colon (153) & 20 & $21 \cdot 2$ & $94(58-146)$ \\
Rectum (154) & 19 & $14 \cdot 5$ & $131(79-205)$ \\
Liver (155) & 3 & $1 \cdot 9$ & $158(32-463)$ \\
Nose (160) & 3 & $0 \cdot 9$ & $333(66-978)$ \\
Larynx (161) & 3 & $4 \cdot 0$ & $75(15-220)$ \\
Lung (162) & 50 & $37 \cdot 5$ & $133(99-176)$ \\
Pleural mesothelioma (163) & 3 & $1 \cdot 1$ & $273(55-800)$ \\
Kidney (180) & 19 & $10 \cdot 7$ & $178(107-278)$ \\
Bladder (181) & 20 & $19 \cdot 0$ & $105(64-163)$ \\
Melanoma of the skin (190) & 9 & $11 \cdot 5$ & $78(36-149)$ \\
Skin cancer(191) & 2 & $7 \cdot 1$ & $28(3-101)$ \\
Brain (193) & 10 & $9 \cdot 8$ & $102(49-188)$ \\
Unspecified (199) & 9 & $9 \cdot 9$ & $91(41-173)$ \\
Hodgkin's disease (201) & 3 & $2 \cdot 1$ & $143(29-419)$ \\
Non-Hodgkin's lymphoma & 9 & $10 \cdot 9$ & $83(38-157)$ \\
$\quad$ (200/2) & 11 & $6 \cdot 2$ & $177(89-318)$ \\
Leukaemia (204) & 269 & 264 & $102(90-115)$ \\
All cancer (140-204) & & &
\end{tabular}

Most welders were registered for mild steel welding. The welders registered for stainless steel welding or with records on stainless steel welding in their work history were categorised in a subcohort for separate analyses.

Asbestos was used until the mid 1970s in most businesses where the boiler welders were employed. Exposure to asbestos used for insulation on older boilers may also have taken place beyond the 1970 s during maintanence of the boilers.

There is no information on individual smoking habits among the cohort members. Studies in the 1960 s indicate a prevalence of daily smoking about $15 \%$ higher for blue collar workers than for other Norwegian men. ${ }^{15} \mathrm{~A}$ corresponding figure was calculated from a survey on smoking habits in 1984 in a cohort of shipyard welders. ${ }^{3}$ Given the high level of education among these skilled craftsmen, the prevalence could be lower than among blue collar workers in general and hence be close to the prevalence among Norwegian men.

\section{SUBJECTS AND METHODS}

The registry of individual welders was used as the source for the names of the cohort members. This part of the registry was chosen because it contained a continuous range of registration numbers of the welders, 5815 in total. Thirty nine welders had applied for registration but failed to pass the exam. An additional 1901 welders had been granted registration for gas welding only. The $\mathbf{5 1 5}$ welders first registered after 1981 were excluded. Twenty subjects could not be identified by name. The seven female welders identi-

Table 2 Observed $(O)$ and expected $(E)$ cases of cancer at selected sites in a subcohort of 606 boiler welders ever welding on stainless steel

\begin{tabular}{lccc}
\hline Cancer site (ICD-7) & $O$ & $E$ & $S I R(95 \%$ CI) \\
\hline Stomach (151) & 3 & $2 \cdot 9$ & $103(21-303)$ \\
Colon (153) & 4 & $3 \cdot 3$ & $121(33-309)$ \\
Rectum (154) & 4 & $2 \cdot 2$ & $182(50-464)$ \\
Liver (155) & 0 & $0 \cdot 3$ & \\
Larynx (161) & 0 & $0 \cdot 6$ & $103(38-226)$ \\
Lung (162) & 6 & $5 \cdot 8$ & $500(0-2800)$ \\
Pleural mesothelioma (163) & 1 & $0 \cdot 2$ & $118(12-424)$ \\
Kidney (180) & 2 & $1 \cdot 7$ & $200(20-128)$ \\
Bladder (181) & 0 & $2 \cdot 9$ & $100(71-135)$ \\
Leukaemia (204) & 2 & $1 \cdot 0$ & \\
All cancer (140-204) & 41 & $41 \cdot 2$ &
\end{tabular}

fied were excluded. A group of 223 foreigners, without permanent addresses in Norway could not be followed up and were therefore excluded. For the remaining 3110 there was information on date of birth for only 1864 . Additional information for these welders was recorded from the files of the businesses. However, the proportion of subjects identified was still insufficient. To improve both identification and individual exposure data, information from the files of correspondance before registration was investigated for the 2638 welders available in this part of the registry.

After that procedure was completed, 153 welders $(4.9 \%)$ could not be identified. Forty four welders who had emigrated during follow up remained under study until the middle of the year of emigration. The final cohort comprised 2957 welders, including a subgroup of 606 stainless steel welders.

The year of registration was the same as the year of recruitment to the cohort. The number of person-years under study was from registration or 1953, whichever was the later. The observed cases of cancer started in 1953, and continued to 1992 or the middle of the year of death. A surrogate for first exposure was established using the first year as a welder according to the information on the available application forms. This surrogate for first exposure was only used to assess the relation between an assumed first time of welding and the development of cancer cases. A development time for cancer was allowed by excluding observed and expected numbers of cases for the first 15 years of exposure or before 1953 for 204 welders exposed before 1938 .

The Cancer Registry of Norway has registered all new cases of cancer occurring in the Norwegian population since 1 January 1953 based on compulsary reporting from hospitals and pathologists. The registration of all new cases is more than $99 \%$ complete for solid tumours.

The expected numbers are based on fiveyear age specific incidences for Norwegian men for each calendar year from 1953 to 1992. The $95 \%$ confidence intervals $(95 \%$ CIs) were estimated on the assumption of a Poisson distribution of events with the use of a two sided test of significance. Standarised incidence rates (SIRs) were the rates between the observed and expected numbers of cases multipled by 100 .

\section{Results}

The cohort comprised 2957 welders contributing 68993 person-years to the study after registration as boiler welders. There were 625 deaths in the whole cohort $v 659$ expected (standardised mortality ratio $($ SMR) $=95$ ), and 269 cases of cancer of all sites were found $v 264$ expected. Fifty cases of lung cancer $v$ 37.5 expected were identified, and an increased incidence of pleural mesothelioma $(\mathrm{O} / \mathrm{E}=3 / 1 \cdot 1)$ was found. The incidence of kidney cancer was increased with 19 cases $v$ 10.7 expected (table 1 ).

Electric arc welders are exposed to electro- 
Table 3 Incidence of all cancer and lung cancer among 2957 boiler welders and a subcohort of stainless steel welders according to period of first registration as a boiler welder

\begin{tabular}{|c|c|c|c|c|c|c|}
\hline \multirow[b]{2}{*}{ Period } & \multicolumn{3}{|c|}{ Boiler welders } & \multicolumn{3}{|c|}{ SS-welders } \\
\hline & $n$ & Cancer $O / E$ & Lung cancer $O / E$ & $n$ & Cancer $O / E$ & Lung cancer $O / E$ \\
\hline $\begin{array}{l}1942-9 \\
1950-9 \\
1960-9 \\
1970-9 \\
1980-2\end{array}$ & $\begin{array}{r}219 \\
618 \\
843 \\
1027 \\
250\end{array}$ & $\begin{array}{r}49 / 50 \cdot 7 \\
112 / 99 \cdot 8 \\
73 / 79 \cdot 6 \\
29 / 29 \cdot 1 \\
6 / 5 \cdot 0\end{array}$ & $\begin{array}{r}7 / 6 \cdot 7 \\
25 / 14 \cdot 7 \\
9 / 12 \cdot 0 \\
7 / 3 \cdot 6 \\
2 / 0 \cdot 5\end{array}$ & $\begin{array}{r}32 \\
70 \\
146 \\
301 \\
57\end{array}$ & $\begin{array}{r}10 / 9 \cdot 2 \\
12 / 10 \cdot 6 \\
9 / 12 \cdot 8 \\
9 / 7 \cdot 7 \\
1 / 0 \cdot 9\end{array}$ & $\begin{array}{l}2 / 1 \cdot 2 \\
1 / 1 \cdot 6 \\
0 / 2 \cdot 0 \\
2 / 0 \cdot 9 \\
1 / 0 \cdot 1\end{array}$ \\
\hline
\end{tabular}

magnetic fields in their work. Reports have suggested excess incidence of leukaemia among electrical workers. ${ }^{16}$ There were 11 cases of leukaemia $v 6.2$ expected in the cohort (SIR 177), five were classified as acute $v$ 2.9 expected (SIR 172). Further, four cases were subclassified as myeloid, three as lymphatic, and three as monocytic. One case remained unclassified. The incidences of brain cancer and lymphomas were not increased. The increased risk of leukaemia differs from previous studies among welders. ${ }^{16}$

However, the increase was not related to a specific subgroup of leukaemia.

There were six cases of lung cancer among stainless steel welders $v \mathbf{5 . 8}$ expected (table 2), and one case of pleural mesothelioma had occured $v 0.2$ expected.

Table 3 shows the incidence of all cancers and lung cancer according to period of first registration. The groups registered in the 1950 s and the early 1980 s are the groups with an increased risk of cancers of all sites. The group registered in the 1950s had an increased incidence of lung cancer $(\mathrm{O} / \mathrm{E}=25 / 14 \cdot 7)$. In those registered after 1970 there were nine cases $v 4 \cdot 1$ expected.

A development time was allowed by excluding observed and expected numbers for the first 15 years after first welding exposure, or exposure before 1953 . There were 245 cases of cancer of all sites $v 248 \cdot 1$ expected. Forty six cases of lung cancer had occurred $v 36 \cdot 1$ expected, and three cases of pleural mesothelioma $v 1.0$ expected. The corresponding figures for the stainless steel welders were 22 cases of cancer of all causes $v 23.0$ expected, only two cases of lung cancer $v 3.4$ expected, and one case of pleural mesothelioma $v 0 \cdot 1$ expected.

\section{Discussion}

The welders in the present cohort are in general highly skilled craftsmen selected by their employers because of their registration. Therefore, it is possible that the cohort to some extent comprises a group of workers selected on the basis of good health. This effect could be of greater significance in the present cohort than in other studies among welders, and even more pronounced in the subcohort of stainless steel welders.

Such selection seems to be supported by the overall SMR of 95, and the incidence of all cancers close to unity (SIR 102), both findings being quite low for welders.

The contrast between the work related exposure among these qualified welders and the control population of Norwegian men is likely to be significant. However, individual information was lacking on the end of exposure as a welder, which made it impossible to stratify the cohort in different exposure groups according to duration of exposure.

Due to changes in welding methods as well as in the composition of the steel alloys of concern, most welders have experienced a complex exposure. An increased risk of cancer in the subcohort of stainless steel welders would have supported the view that the development of cancer among welders is associated with exposure to hexavalent chromium. ${ }^{4}$ However, there was an increased incidence of lung cancer in the total cohort (SIR 133), the result among stainless steel welders was close to unity (SIR 103). When allowing for a development time from an estimated first exposure as a welder or stainless steel welder, the SIRs were 128 for the total cohort and only 58 for the subcohort. Hence, the present results do not seem to support the view that the excess of lung cancer in the whole cohort is related to exposure during stainless steel welding.

There was an excess incidence of cancer of the kidney in the total cohort (SIR 178). The corresponding SIR was 113 among the stainless steel welders. Asbestos ${ }^{17}$ and metal fumes are the exposures that hypothetically might have contributed to the slightly increased risk. No subjects had lung cancer secondary to cancer of the kidney.

The result for bladder cancer was close to unity (SIR 105). There was no excess of cancer in the upper respiratory tract. No direct information on smoking habits was available in the registry. A survey on smoking habits in Norway in 1964 indicated about 15\% more smokers among blue collar workers than other men. ${ }^{15}$ The low incidence of cancers related to smoking, except lung cancer, could possibly indicate that the excess of daily smokers was lower in the present cohort than among other blue collar workers. ${ }^{181920}$ The modifying effect of smoking alone on the incidence of lung cancer could amount to an excess SIR of up to $20 .{ }^{18}$

The highest incidence of lung cancer (SIR 170) in the total cohort was found among those welders who were registered during the 1950s. There were two cases of lung cancer among 32 stainless steel welders registered during the $1940 \mathrm{~s} v 1.2$ expected. The exposure to welding fumes among welders in these early decades seems to have been high. ${ }^{31021}$ The incidence of lung cancer did not increase in the total cohort (SIR 127) when allowing for a development time of 15 years since the 
estimated first exposure. In the subcohort of stainless steel welders the corresponding figures were two cases of lung cancer $v 3.7$ expected. All stainless steel welders had also been mild steel welders. For most of the cohort members the first exposure to mild steel welding fumes took place before the first exposure to stainless steel welding fumes.

The present results seem to indicate that welders carry a small excess risk of lung cancer. The overall excess risk cannot be attributed to the subcohort of stainless steel welders. Confounding factors, like asbestos exposure and tobacco smoking, probably account for a major part of the excess risk. The specific effect from exposure to welding fumes is disputable.

We thank Heinz Sveen from the Labour Inspectorate of Norway for cooperation throughout the study. This project was financed by the Bundesministerium für Forschung and Technologie, and the Royal Norwegian Council for Scientific and Industrial Research. We received additional support from the Working Environment Fund of the Confederation of Norwegian Business and Industry, and the Directorate of Labour Inspection.

1 Simonato L, Fletcher AC, Andersen A, et al. A historica prospective study of European stainless steel, mild steel, and shipyard welders. $\mathrm{Br} f$ Ind Med 1991;48:145-54.

2 Melkild A, Langård S, Andersen A, Stray Tønnessen JN. Incidence of cancer among welders and other workers in Norwegian shipyard. Scand $₹$ Work Environ Health 1989 15:387-94.

3 Danielsen TE, Langård S, Andersen A, Knudsen $\varnothing$. Incidence of cancer among welders of mild steel and other shipyard workers. Br f Ind Med 1993;50:1097-103.

4 Sjøgren B, Hansen KS, Kjuus H, Persson PG. Exposure to stainless steel welding fumes and lung cancer: a metastainless steel welding fumes and lung can
analysis. Occup Environ Med 1994;51:335-6.

5 Becker N, Claude J, Frentzel-Beyme R. Cancer risk of arc welders exposed to fumes containing chromium and nickel. Scand $₹$ Work Environ Health 1985;11:75-82.

6 Becker N, Chang-Claude J, Frentzel-Beyme R. Risk of cancer for arc welders in the Federal Republic of Germany: results of a second follow up (1983-8). Br 7 Ind Med 1991;48:675-83.

Beaumont J, Weiss NS. Lung cancer among welders. $f$ Occup Med 1981;23:839-44.

8 Sjögren B, Gustavsson A, Hedstrøm L. Mortality in two cohorts of welders exposed to high and low levels of hexavalent chromium. Scand $\mathcal{f}$ Work Environ Health 1987;13:247-51.

9 Moulin J, Wild P, Haguenoer JM, Faucon D, De Gaudemaris R, Mur JM, et al. A mortality study among mild steel and stainless steel welders. Br F Ind Med 1993; 50:234-43.

10 Tola S, Kalliomäki P-L, Pukkala E, Asp S, Korkala M-L Incidence of cancer among welders, platers, machinists, and pipe fitters in shipyards and machine shops. Br f Ind and pipe fitters in ship

11 Steenland K, Beaumont J, Elliot L. Lung cancer in mild steel welders. Am $\mathcal{F}$ Epidemiol 1991;133:220-9.

12 Peto J. Cancer morbidity and mortality studies of welder In: Stern RM, Berlin A, Fletcher AC, Järvisalo J, ed. Proceedings of the International Conference on Health Hazards and Biological Effects of Welding Fumes and Gases, Copenhagen, 18-21 February, 1985. Amsterdam: Excerpta Medica, 1986:423-34

13 Langård S. Confounding and effect-modifying factors in epidemiological studies in welders. In: Stern RM, Berlin A, Fletcher AC, Järvisalo J, ed. Proceedings of the A, Fletcher AC, Jarvisalo J, ed. Proceedings of the Effects of Welding Fumes and Gases, Copenhagen, 18-21 Effects of Welding Fumes and Gases, Copenhagen, 18-21 February,

14 International Agency for Research of Cancer. Chromium nickel and welding. LARC Monogr Eval Carcinog Risk Hum 1990;49:463-74.

15 Zeiner-Henriksen T. Røykevaner i den norske befolkning (Smoking habits in the Norwegian population). Tidsskr Nor Lageforen 1976;96:617-20.

16 Stern RM. Cancer incidence among welders: possible effects of exposure to extremely low frequency electromagnetic radiation (ELF) and to welding fumes. Environ Health Perspect 1987;76:221-9.

17 Hammond EC, Selikoff IJ, Seidman H. Asbestos exposure cigarette smoking and death rates. Ann NY Acad Sci 1979;330:473-90.

18 Axelson $O$. Aspects of confounding in occupational health epidemiology. Scand $\mathcal{f}$ Work Environ Health 1978;4: 98-102.

19 Steenland K, Beaumont J, Halperin W. Methods of control for smoking in occupational cohort mortality studies. Scand $f$ Work Environ Health 1984;10:143-9.

20 Siemiatycki J, Wacholder S, Dewar R, Cardis E Greenwood C, Richardson L. Degree of confounding bias related to smoking, ethnic group, and socioeconomic status in estimates of the associations between occupation and cancer. $f$ Occ Med 1988;30:617-25

21 Stern RM. Assessment of risk of lung cancer for welders. Arch Environ Health 1983;38:148-55.

\section{Instructions to authors}

Three copies of all submissions should be sent to: The Editor, Occupational and Environmental Medicine, BMJ Publishing Group, BMA House, Tavistock Square, London WC1H 9JR, UK. All authors should sign the covering letter as evidence of consent to publication. Papers reporting results of studies on human subjects must be accompanied by a statement that the subjects gave written, informed consent and by evidence of approval from the appropriate ethics committee. These papers should conform to the principles outlined in the Declaration of Helsinki (BMF 1964; ii:177).
If requested, authors shall produce the data on which the manuscript is based, for examination by the Editor.

Authors are asked to submit with their manuscript the names and addresses of three people who they consider would be suitable independent reviewers. They will not necessarily be approached to review the paper.

Papers should include a structured abstract of not more than 300 words, under headings of Objectives, Methods, Results, and Conclusions. Please include up to three keywords or key terms to assist with indexing. 